\title{
PENGARUH PERCEIVED VALUE, TRUST, DAN CUSTOMER SATISFACTION TERHADAP CUSTOMER LOYALTY PENGGUNA APLIKASI M-BANKING BCA DI JAKARTA BARAT
}

\author{
Clarisa Stefanie dan Carunia Mulya Firdausy \\ Program Studi S1 Manajemen Fakultas Ekonomi \& Bisnis Universitas Tarumanagara, Jakarta \\ Email:clarisa.115170110@stu.untar.ac.id \\ caruniaf@pps.untar.ac.id
}

\begin{abstract}
This study examines the effect of perceived value, trust, and customer satisfaction on customer loyalty to BCA m-banking users in West Jakarta. The population of this research is all BCA m-banking users in Jakarta. The sample in this study was 100 respondents who used the BCA m-banking application located in West Jakarta. The sampling technique used was convenience sampling, while non-probability sampling was used for sample selection by distributing online questionnaires through a google form which was then processed using the Smart PLS assistance program. The results showed that perceived value, trust, and customer satisfaction had a positive relationship with customer loyalty. Therefore, it is a must for BCA to give serious attention to these variables to improve its customers' loyalty in using $B C A \mathrm{~m}$ banking.
\end{abstract}

Keywords: Perceived Value, Trust, Customer Satisfaction, Customer Loyalty, m-banking BCA.

\begin{abstract}
Abstrak: Penelitian ini bertujuan untuk menguji pengaruh perceived value, trust, dan customer satisfaction terhadap customer loyalty pengguna m-banking BCA di Jakarta Barat. Populasi dari penelitian ini adalah seluruh pengguna m-banking BCA di Jakarta. Sampel pada penelitian ini adalah 100 responden yang menggunakan aplikasi $m$-banking BCA berlokasi di Jakarta Barat. Teknik pengambilan sampel yang digunakan adalah convenience sampling sedangkan untuk pemilihan sampel menggunakan non-probability sampling dengan menyebarkan kuesioner secara online via google form yang kemudian diolah menggunakan bantuan program Smart PLS. Hasil penelitian menunjukkan bahwa perceived value, trust, dan customer satisfaction memiliki hubungan positif dengan customer loyalty. Oleh karena itu, BCA harus memperhatikan variabel-variabel ini untuk meningkatkan customer loyalty dalam penggunaan m-banking BCA.
\end{abstract}

Kata kunci: Perceived Value, Trust, Customer Satisfaction, Customer Loyalty, m-banking $B C A$.

\section{LATAR BELAKANG}

Perkembangan teknologi dan informasi sekarang ini telah menciptakan berbagai peluang untuk bisnis dimana setiap transaksi bisnis yang dilakukan sekarang ini pada umumya dilakukan melalui elektronik. Dengan berkembangnya teknologi dan komunikasi, setiap orang sekarang ini dapat dengan mudah melakukan transaksi jual-beli. Selain untuk pemanfaatan informasi, penggunaan teknologi dan informasi juga dapat digunakan sebagai sarana untuk melakukan transaksi perbankan. Oleh karena itu, kondisi pada saat ini berbagai perusahaan mulai mengikuti perkembangan teknologi dan informasi. 
Dalam bidang perbankan cara yang digunakan untuk mengimbangi perkembangan teknologi dan informasi adalah dengan menggunakan mobile banking atau biasa dikenal dengan $m$-banking yang merupakan suatu layanan inovatif yang ditawarkan oleh bank sehingga memungkinkan pengguna kegiatan transaksi perbankan melalui smartphone (Agus, 2005:83). Mobile Banking memungkinkan nasabah bank untuk mengakses rekening dan informasi umum mengenai produk dan jasa yang ditawarkan bank. Dengan adanya mobile banking dapat memudahkan nasabah bank untuk bertransaksi lebih cepat tanpa mengenal ruang dan waktu.

Di Indonesia, layanan mobile banking telah digunakan oleh PT Bank Central Asia Tbk, atau biasa dikenal dengan BCA sejak tahun 2011. Fitur-fitur yang ditawarkan dalam layanan mobile banking BCA diantaranya adalah cek saldo rekening, riwayat transaksi, pemindahan dan antar rekening maupun antar bank, membayar tagihan dan masih banyak fitur yang disediakan.

Pada kuartal pertama tahun 2021 transaksi mobile banking BCA meningkat hingga $37,1 \%$. Peningkatan layanan transaksi digital meningkat seiring dengan perilaku masyarakat yang mulai beralih ke digital karena pandemi. Dibandingkan dengan periode tahun lalu, BCA mencatat adanya peningkatan transaksi melalui mobile banking. Hal tersebut dikarenakan BCA mendorong nasabah untuk mengoptimalkan penggunaan digital banking (https://keuangan.kontan.co.id/).

Kendala utama pada aplikasi $m$-banking BCA saat ini antara lain hanya dapat mengelola satu rekening yang telah terdaftar pada sistem BCA. Selain itu, aplikasi $m$-banking BCA hanya dapat digunakan pada ponsel berbasis android maupun iOS di dalam negeri. Fitur keamanan aplikasi m-banking BCA hanya berupa pin dan kode akses dibandingkan dengan aplikasi mobile banking lain yang sudah menggunakan biometric authentication. Masalah-masalah tersebut dapat mempengaruhi customer loyalty pengguna aplikasi m-banking BCA.

Dalam literatur diungkapkan bahwa customer loyalty dipengaruhi oleh beberapa faktor. Chen dan Tsai (2008) meneliti dalam penelitiannya menyatakan bahwa customer loyalty dapat dipengaruhi oleh perceived value. Hal ini dikarenakan dengan semakin baiknya penilaian dari konsumen maka dapat meningkatkan customer loyalty pada suatu produk. Selanjutnya, Haron, et al. (2020), menyatakan dalam penelitiannya bahwa trust memiliki pengaruh terhadap customer loyalty. Semakin tingginya kepercayaan yang dirasakan oleh seseorang terhadap suatu produk dapat membantu meningkatkan customer loyalty dari perusahaan. Bontis et al., (2007) meneliti hubungan antara customer satisfaction dan customer loyalty industri perbankan di Amerika Utara dan menemukan bahwa ada hubungan positif antara customer satisfaction dan customer loyalty. Tanisah dan Maftuhah (2015) melakukan penelitian mengenai perceived value, trust dan customer satisfaction terhadap customer loyalty. Hasil penelitian tersebut didapatkan hasil bahwa perceived value, trust, dan customer satisfaction memiliki hubungan yang positif terhadap customer loyalty.

Dari beberapa penelitian yang telah dilakukan dapat disimpulkan bahwa perceived value, trust, dan customer satisfaction merupakan faktor penting yang dapat meningkatkan customer loyalty terhadap BCA. Oleh karena itu, penelitian ini ingin mengkaji kembali apakah variabel-variabel tersebut berpengaruh terhadap customer loyalty. Lebih spesifik, penelitian ini bertujuan meneliti pengaruh perceived value, trust, dan customer satisfaction terhadap customer loyalty pengguna aplikasi m-banking BCA di Jakarta Barat.

\section{KAJIAN TEORI}

Landasan teori penelitian ini yakni Teori Planned Behavior (TPB) yang dikemukakan oleh Ajzen (1991). Dalam penelitian yang dilakukan oleh Badara et al. (2013), customer loyalty diukur dari niat perilaku pelanggan dalam hal niat membeli. Oleh karena itu, theory of planned behavior akan digunakan untuk mendukung kerangka penelitian untuk memahami customer 
loyalty. Theory of planned behavior membuktikan bahwa niat dapat menjadi penentu terbaik dari perilaku individu. Dengan demikian, individu yang memiliki niat kuat cenderung terlibat dalam perilaku tersebut dibandingkan dengan yang memiliki niat rendah.

Perceived value merupakan suatu pertukaran antara apa yang telah diperoleh konsumen dengan apa yang telah diberikan oleh konsumen (Turangan dan Keni, 2015). Trust merupakan suatu elemen penting dalam mengembangkan hubungan dengan pelanggan (Mahmoud et al., 2018). Customer satisfaction merupakan salah satu bidang yang paling banyak diteliti dalam banyak studi pariwisata karena sangat penting dalam menentukan keberhasilan dan keberlangsungan bisnis pariwisata (Gursoy et al., 2007). Customer loyalty dapat diartikan sebagai perilaku konsumen yang memiliki sikap baik terhadap penyedia layanan, merekomendasikan suatu layanan kepada konsumen lain dan menunjukkan sikap untuk membeli atau menggunakan kembali (Dagger dan O'Brien, 2010).

Keshavarz dan Jamshidi (2018) dalam penelitiannya pada industri perhotelan menemukan bahwa perceived value oleh pelanggan memberikan pengaruh terhadap customer loyalty. Haron, et al. (2020), dalam penelitiannya pada salah satu bank di Malaysia menyatakan bahwa trust memiliki pengaruh terhadap customer loyalty pada suatu produk atau jasa yang ditawarkan. Amin (2016) melakukan penelitian mengenai internet banking, dari data yang didapatkan menyebutkan bahwa customer satisfaction memberi pengaruh positif terhadap customer loyalty.

Loyalitas pelanggan pada penelitian ini dipengaruhi oleh perceived value, trust, dan customer satisfaction. Loyalitas merupakan komitmen pelanggan saat ini sehubungan dengan toko, merek, dan penyedia layanan tertentu, ketika ada alternatif lain yang dapat dipilih pelanggan saat ini (Shankar et al., 2003) hal tersebut membentuk sikap positif dengan menghasilkan perilaku pembelian atau penggunaan secara berulang dari waktu ke waktu.

Dari uraian penelitian yang dilakukan sebelumnya di atas, maka model penelitian ini dirumuskan sebagai berikut (gambar 1):

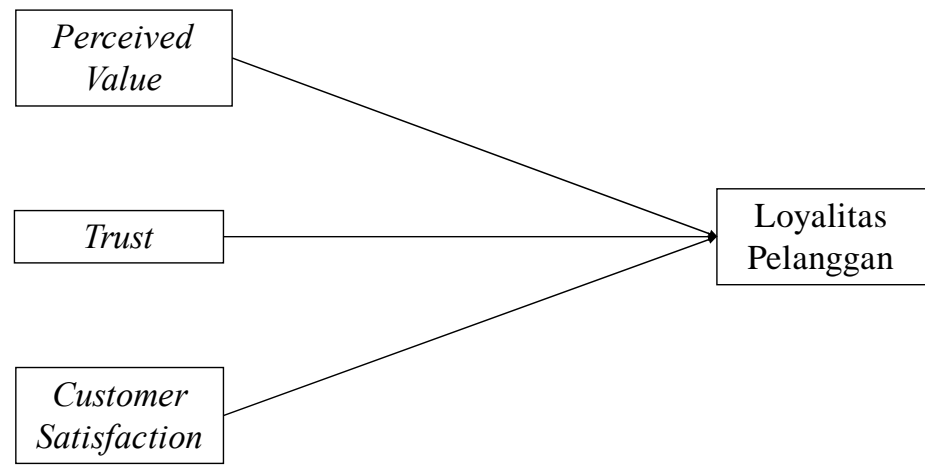

Gambar 1.

Kerangka Pemikiran

Berdasarkan kerangka pemikiran tersebut, dan kaitan antar variabel dari penelitian terdahulu dapat dirumuskan hipotesis sebagai berikut:

$\mathrm{H}_{1}$ : Perceived value berpengaruh positif dan signifikan terhadap customer loyalty pengguna aplikasi m-banking BCA di Jakarta Barat.

$\mathrm{H}_{2}$ : Trust berpengaruh positif dan signifikan terhadap customer loyalty pengguna aplikasi $m$ banking BCA di Jakarta Barat.

$\mathrm{H}_{3}$ : Customer satisfaction berpengaruh positif dan signifikan terhadap customer loyalty pengguna aplikasi $m$-banking BCA di Jakarta Barat. 


\section{METODOLOGI}

Desain penelitian ini menggunakan desain penelitian deskriptif. Karakteristik dalam desain ini dideskripsikan dengan menggunakan analisis statistik berdasarkan data yang diambil melalui kuesioner. Kuesioner akan disebarkan kepada pengguna aplikasi m-banking BCA di Jakarta Barat. Populasi dalam penelitian ini adalah seluruh pengguna aplikasi $m$-banking BCA di Jakarta Barat. Dikarenakan populasi dari seluruh pengguna aplikasi $m$-banking di Jakarta Barat tidak dapat diperoleh datanya, maka penelitian ini menggunakan sampel yaitu pengguna aplikasi m-banking BCA yang berdomisili di daerah Jakarta Barat saja. Teknik pemilihan sampel yang digunakan dalam penelitian ini adalah non-probability sampling. Sedangkan, dalam pengumpulan data di lapangan responden yang menjadi sampel dilakukan dengan teknik convenience sampling. Cara pemilihan sampel adalah dengan melakukan screening question dalam kuesioner agar dapat dengan mudah mendapatkan responden yang sesuai dengan kriteria. Jumlah sampel yang diambil dalam penelitian ini sebanyak 100 responden. Dalam penetapan sampel tersebut ditetapkan kriteria bahwa responden harus merupakan pengguna aplikasi m-banking BCA di Jakarta Barat.

Dalam mengumpulkan data sampel digunakan kuesioner. Kuesioner ini disebarkan kepada responden yang dapat dijadikan sampel dalam penelitian ini, yaitu pengguna aplikasi m-banking BCA di Jakarta Barat dengan menggunakan google form. Penyebaran kuesioner dilakukan secara online melalui media sosial seperti Line dan WhatsApp kepada calon responden. Sumber responden Line dan WhatsApp berasal dari grup chat baik dengan teman sekolah, teman kampus maupun saudara. Hal ini dilakukan dengan tujuan untuk menghemat waktu dan biaya.

Dalam mengkualifikasi indikator dari masing-masing variabel digunakan skala likert. Interval skala likert ini sebagai berikut:

$1=$ Sangat Tidak Setuju (STS)

2 = Tidak Setuju (TS)

$3=\operatorname{Netral}(\mathrm{N})$

$4=$ Setuju $(\mathrm{S})$

5 = Sangat Setuju (SS)

\section{HASIL ANALISIS DATA}

\section{Hasil Analisis Validitas}

Analisis validitas dengan menggunakan teknik SEM terbagi menjadi validitas konvergen dan validitas diskriminan. Validitas konvergen menggunakan pendekatan Average Variance Extracted ( $A V E$ ), dimana setiap indikator nilai $A V E$ harus melebihi 0,5. Sedangkan validitas diskriminan menggunakan pendekatan Heterotrait-Monotrait Ratio (HTMT) dimana seluruh nilai pada tiap indikator kurang dari $0.9(<0.9)$. Hasil uji validitas konvergen dapat dilihat pada tabel 1 .

\section{Tabel 1}

Hasil Uji Validitas Konvergen (AVE)

\begin{tabular}{|l|l|}
\hline \multicolumn{1}{|c|}{ Variabel } & \multicolumn{1}{c|}{ AVE } \\
\hline Perceived Value & 0.657 \\
\hline Trust & 0.622 \\
\hline Customer Satisfaction & 0.720 \\
\hline
\end{tabular}


Customer Loyalty

0.655

Tabel 1 ditampilkan hasil uji validitas konvergen yang memiliki nilai diatas 0.5. Dengan demikian, seluruh variabel dapat digunakan sebagai variabel penelitian.

Hasil dari Heterotrait-Monotrait Ratio menunjukkan bahwa seluruh nilai pada tiap indikator sudah kurang dari 0.9 (<0.9) sehingga dapat dikatakan bahwa hasil dari analisis Heterotrait-Monotrait Ratio tersebut memenuhi syarat. Hasil uji validitas diskriminan dapat dilihat pada tabel 2.

Tabel 2

Hasil Uji Validitas Diskriminan (HTMT)

\begin{tabular}{|l|l|l|l|l|}
\hline & $\begin{array}{c}\text { Customer } \\
\text { Loyalty }\end{array}$ & $\begin{array}{c}\text { Customer } \\
\text { Satisfaction }\end{array}$ & $\begin{array}{c}\text { Perceived } \\
\text { Value }\end{array}$ & Trust \\
\hline $\begin{array}{l}\text { Customer } \\
\text { Loyalty }\end{array}$ & & & & \\
\hline $\begin{array}{l}\text { Customer } \\
\text { Satisfaction }\end{array}$ & 0.674 & 0.723 & & \\
\hline $\begin{array}{l}\text { Perceived } \\
\text { Value }\end{array}$ & 0.649 & 0.740 & 0.677 & \\
\hline Trust & 0.634 & & \\
\hline
\end{tabular}

Pada tabel 2 menampilkan hasil uji validitas diskriminan yang memiliki nilai diatas 0.9. Dengan demikian, seluruh variabel dapat digunakan sebagai variabel penelitian.

\section{Hasil Analisis Reliabilitas}

Uji reliabilitas menggunakan composite reliability. Hasil yang didapatkan harus diatas 0,7 agar dapat dikatakan reliabel. Hasil analisis reliabilitas yang diukur dengan composite reliability, memiliki nilai lebih dari 0.7 untuk keempat variabel yaitu perceived value, trust, customer satisfaction dan customer loyalty. Hasil uji reliabilitas dapat dilihat pada tabel 3.

\section{Tabel 3}

Hasil Uji Reliabilitas

\begin{tabular}{|l|l|}
\hline \multicolumn{1}{|c|}{ Variabel } & Composite Reliability \\
\hline Perceived Value & 0.884 \\
\hline Trust & 0.891 \\
\hline $\begin{array}{l}\text { Customer } \\
\text { Satisfaction }\end{array}$ & 0.911 \\
\hline Customer Loyalty & 0.905 \\
\hline
\end{tabular}

\section{Hasil Analisis Multikolinearitas}

Uji multikolinearitas dapar dilihat dari nilai variance inflation factor (VIF) yang sering digunakan untuk mengevaluasi kolinearitas dari indikator formatif. Nilai VIF sebesar 5 atau diatas 5, menunjukkan masalah kolinearitas kritis diantara indikator konstruksi yang diukur 
secara formal. Maka dari itu penelitian ini memiliki batas nilai VIF tidak lebih dari 5. Hasil analisis multikolinearitas dapat dilihat pada tabel 4. 


\section{Tabel 4}

Hasil Analisis Multikolinearitas

\begin{tabular}{|l|c|}
\hline \multicolumn{1}{|c|}{ Variabel } & $\begin{array}{c}\text { Variance Inflation Factor } \\
\text { (VIF) }\end{array}$ \\
\hline Perceived Value & 1.765 \\
\hline Trust & 1.876 \\
\hline Customer Satisfaction & 2.028 \\
\hline
\end{tabular}

\section{Hasil Koefisien Determinasi $\left(\mathbf{R}^{2}\right)$}

Koefisien determinasi atau $r$-square dapat menjelaskan mengenai pengaruh variabel eksogen terhadap variabel endogen. Nilai koefisien determinan dibagi menjadi 3 bagian yaitu $0.75,0.50$, dan 0.25 , dimana masing-masing menjelaskan tingkat besar, sedang, atau kecil (Hair et al., 2019). Hasil analisis koefisien determinasi dapat dilihat pada tabel 5.

\section{Tabel 5}

Hasil Analisis Koefisien Determinasi $\left(\mathrm{R}^{2}\right)$

\begin{tabular}{|l|l|}
\hline \multicolumn{1}{|c|}{ Variabel } & $R$ square \\
\hline Customer Loyalty & 0.432 \\
\hline
\end{tabular}

\section{Hasil Effect Size $\left(\mathbf{f}^{2}\right)$}

Effect size ditentukan melalui nilai model yang terbagi menjadi tiga kategori yaitu 0.02 yang menandakan efek model yang kecil, 0.15 menandakan efek model yang sedang, dan 0.35 menyatakan efek model yang besar (Hair et.al., 2014). Hipotesis dapat didukung apabila path coefficients memiliki nilai yang berkisar antara -1 sampai +1 dan nilai yang terdapat pada $p$-value lebih kecil dari $0.05(<0.05)$.

Tabel 6

\begin{tabular}{|l|l|}
\hline \multicolumn{2}{|c}{ Hasil Effect Size $\left(\mathrm{f}^{2}\right)$} \\
\hline Customer Satisfaction & Customer Loyalty \\
\hline Perceived Value & 0.068 \\
\hline Trust & 0.059 \\
\hline
\end{tabular}

\section{Hasil Predictive Relevance $\left(\mathbf{Q}^{2}\right)$}

Uji relevansi prediksi berfungsi untuk mengukur seberapa baik nilai observasi serta estimasi parameter variabel. Predictive relevance atau biasa disebut $Q$-Square dapat dikatakan baik apabila memiliki nilai lebih besar daripada 0 (>0) (Hair et al., 2011). Hasil analisis predictive relevance pada tabel 7 menyimpulkan bahwa hubungan variabel dalam penelitian ini dianggap relevan karena $\mathrm{Q}$ square menunjukkan lebih dari 0 . 
Tabel 7

Hasil Predictive Relevance $\left(\mathrm{Q}^{2}\right)$

\begin{tabular}{|l|l|}
\hline Variabel & Q square \\
\hline Customer Loyalty & 0.270 \\
\hline
\end{tabular}

\section{Hasil Pengujian Hipotesis}

Pada penelitian ini, pengujian data dilakukan dengan menggunakan uji Bootstrapping untuk menguji antara hipotesis $\mathrm{X}$ dan $\mathrm{Y}$. Adapun pengujian tersebut dilakukan untuk mendapatkan bukti adanya pengaruh positif atau tidak berpengaruh postif perceived value, trust, dan customer satisfaction terhadap customer loyalty pengguna aplikasi m-banking BCA di Jakarta Barat. Hasil pengujian hipotesis dapat dilihat pada tabel 8.

\section{Tabel 8}

Hasil Pengujian Hipotesis

\begin{tabular}{|l|l|l|}
\hline \multicolumn{1}{|c|}{ Hipotesis } & \multicolumn{1}{c|}{ Nilai } & Keterangan \\
\hline $\mathrm{H}_{1}:$ Perceived Value $\square$ Customer Loyalty & $\begin{array}{l}\beta=0.240 \\
p \text {-value }=0.017\end{array}$ & Tidak Ditolak \\
\hline $\mathrm{H}_{2}:$ Trust $\square$ Customer Loyalty & $\begin{array}{l}\beta=0.263 \\
p \text {-value }=0.014\end{array}$ & Tidak Ditolak \\
\hline $\begin{array}{l}\mathrm{H}_{3}: \text { Customer Satisfaction } \square \text { Customer } \\
\text { Loyalty }\end{array}$ & $\begin{array}{l}\beta=0.275 \\
p \text {-value }=0.014\end{array}$ & Tidak Ditolak \\
\hline
\end{tabular}

Setelah menguji ketiga hipotesis yang ada dalam penelitian ini, didapatkan hasil bahwa semua variabel berpengaruh positif dan signifikan. Sehingga pada hipotesis ini dapat disimpulkan bahwa perceived value, trust, dan customer satisfaction memiliki pengaruh yang signifikan terhadap customer loyalty.

\section{DISKUSI}

Perceived Value berpengaruh positif dan signifikan terhadap Customer Loyalty. Hal ini sejalan dengan penelitian Bernarto dan Patricia (2017) menunjukkan perceived value memiliki efek positif pada customer loyalty. Trust berpengaruh positif dan signifikan terhadap Customer Loyalty. Hal tersebut sejalan dengan penelitian dari Hoq, et al. (2010) yang menunjukkan trust memiliki pengaruh positif pada customer loyalty. Customer Satisfaction berpengaruh positif dan signifikan terhadap Customer Loyalty. Hal ini sejalan dengan penelitian sebelumnya oleh Andianto dan Firdausy (2020) yang menunjukkan customer satisfaction memiliki efek positif terhadap customer loyalty. Maka dapat disimpulkan bahwa apabila perceived value terhadap aplikasi m-banking BCA semakin baik maka dapat membantu meningkatkan customer loyalty. BCA perlu mempertahankan kepercayaan pengguna aplikasi m-banking BCA agar dapat meningkatkan customer loyalty. Customer satisfaction memiliki dampak yang besar terhadap customer loyalty.

\section{KESIMPULAN}

Berdasarkan hasil dan pembahasan yang dilakukan pada bab sebelumnya mengenai pengujian variabel perceived value, trust, dan customer satisfaction terhadap customer loyalty 
pengguna aplikasi m-banking bank BCA di Jakarta Barat maka dapat disimpulkan sebagai berikut:

1. Perceived value berpengaruh positif dan signifikan terhadap customer loyalty pada pengguna aplikasi m-banking BCA di Jakarta Barat.

2. Trust berpengaruh positif dan signifikan terhadap customer loyalty pada pengguna aplikasi m-banking BCA di Jakarta Barat.

3. Customer satisfaction berpengaruh positif dan signifikan terhadap customer loyalty pada pengguna aplikasi m-banking BCA di Jakarta Barat.

\section{Saran}

Bagi penelitian selanjutnya, disarankan untuk menambahkan variabel lain sehingga dapat membuat penelitian ini semakin berkembang dan memiliki manfaat yang lebih. Kemudian perluasan batasan wilayah menjadi di Jakarta atau di luar Jakarta dan penambahan jumlah sampel untuk penelitian juga dapat dilakukan agar hasil data dari penelitian ini semakin menyerupai kondisi asli di lapangan. Hal tersebut didasarkan pada nilai $R$-square yaitu sebesar $43,2 \%$.

\section{DAFTAR PUSTAKA}

Ajzen, I. (1991). The theory of planned behavior. Organizational behavior and human decision processes, 50(2), 179-211.

Amin, M. (2016). Internet banking service quality and its implication on e-customer satisfaction and e-customer loyalty. International journal of bank marketing, 34(3), 280306.

Andianto, K., \& Firdausy, C. M. Pengaruh Perceived Value, Perceived Quality dan Customer Satisfaction terhadap Customer Loyalty Warunk Upnormal di Jakarta. Jurnal Manajerial Dan Kewirausahaan, 2(3), 758-764.

Badara, M. S., Nik Mat, N. K., Mujtaba, A. M., Al-Refai, A. N., Badara, A. M., \& Abubakar, F. M. (2013). Direct Effect of Service Quality Dimensions on Customer Satisfaction and Customer Loyalty in Nigerian Islamic Bank. Management, 3(1), 6-11.

Bernarto, I., \& Patricia. (2017). Pengaruh Perceived Value, Customer Satisfaction dan Trust terhadap Customer Loyalty Restoran XYZ di Tangerang. Journal for Business and Entrepreneurship, 1(1).

Bontis, N., Booker, L. D., \& Serenko, A. (2007). The mediating effect of organizational reputation on customer loyalty and service recommendation in the banking industry. Management Decision, 45(9), 14261445.https://doi.org/10.1108/00251740710828681

Dagger, T. S and O'Brien, T. K. (2010). Does experience matter? Differences in relationship benefits, satisfaction, trust, commitment and loyalty for novice and experienced service users. European Journal of Marketing, Vol. 44 No. 9/10

Gursoy, D., McCleary, K. W. \& Lepsito, L. R. (2007). Propensity to complain: effects of personality and behavioral factors. Journal of Hospitality \& Tourism Research, 31 (3), 358-386.

Haron, R., Subar, N. A., \& Ibrahim, K. (2020). Service quality of Islamic banks: satisfaction, loyalty and the mediating role of trust. Islamic Economic Studies, 28(1), 3-23.

Hoq, M. Z., Sultana, N., \& Amin, M. (2010). The effect of trust, customer satisfaction and image on customers' loyalty in islamic banking sector. South asian journal of management, 17(1), 70 . 
Keshavarz, Y., \& Jamshidi, D. (2018). Service quality evaluation and the mediating role of perceived value and customer satisfaction in customer loyalty. International Journal of Tourism Cities, 4(2), 220-244. https://doi.org/10.1108/IJTC-09-2017-0044

Kontan. (2021) Transaksi mobile banking Bank BCA melonjak 37,1\% pada kuartal I 2021 (Retrieved from: https://keuangan.kontan.co.id/news/transaksi-mobile-banking-bankbca-melonjak-371-pada-kuartal-i-2021)

Shankar, V., Smith, A. K., \& Rangaswamy, A. (2003). Customer satisfaction and loyalty in online and offline encounters. International Journal of Research in Marketing, 20(2), 153-175.

Tanisah, \& Maftuhah, I. (2015). The Effects of Service Quality, Customer Satisfaction, Trust, And Perceived Value Towards Customer Loyalty. Jurnal Dinamika Manajemen, 6(1), 55-61.

Turangan, J. A., \& Keni, K. (2015). Pengaruh Kepercayaan, Nilai yang Dipersepsikan, Diferensiasi dan Kualitas Pelayanan terhadap Word of Mouth Marketing pada Mahasiswa Universitas Tarumanagara di Jakarta The Influence of Trust, Perceived Value, Differentiation and Service Quality on Word of Mouth. Prosiding Seminar Nasional Kewirausahaan \& Inovasi Bisnis V, 451-462. 